\title{
Survey of the respiratory health of the workers of a talc producing factory
}

\author{
Pascal Wild, Michèle Réfrégier, Guy Auburtin, Bernard Carton, Jean-Jacques Moulin
}

\begin{abstract}
Objectives-To assess the effect of an occupational exposure to talc dust on respiratory health.

Methods-166 talc millers from a French factory underwent spirometry and filled in a standardised respiratory questionnaire during their annual medical visit in 1989. A full sized chest radiograph taken in 1987 for the subjects hired before 1982 was also available, for the others a radiograph taken when hired was used. Radiography was repeated in 1992 for all subjects still active at this date $(n=139)$. The occupational exposure to talc dust was characterised for each workplace with 1440 personal samples collected since 1986 and by semiquantitative estimates of the historical exposure.
\end{abstract}

Results-The geometric mean (range) of estimated exposure was $1.87(0.5$ to 50$)$ $\mathrm{mg} / \mathrm{m}^{3}$ and the estimated cumulative exposure at the date of spirometry was $>150 \mathrm{y} \mathrm{mg} / \mathrm{m}^{3}$ for 41 subjects. After adjustment for smoking in a linear model the standardised residual values of both forced vital capacity and forced expiratory volume in one second decreased significantly with increasing exposure. The prevalence of dyspnoea also increased after adjustment for smoking categories and age in a logistic regression. The prevalence of small radiological opacities was significantly related to age and to the exposure after adjustment for age and smoking categories. The incidence of new opacities between the two radiographs (11 new opacities with a profusion higher than $0 / 1$ ) was significantly related to smoking (10 out of 11 are smokers) but not to the exposure.

Conclusion-This study shows an effect of high levels of talc dust both on functional variables and on the prevalence of small radiological images, but provides no clear evidence about the possible effect of present levels of exposure.

(Occup Environ Med 1995;52:470-477)

Keywords: talc dust; respiratory health

Guidelines on occupational exposure to talc dust are heterogeneous across countries. Although specific recommendations exist in some countries (United States of America, Germany) in others talc dust is considered as inert dust with no specific toxicity. Thus standards vary from $1 \mathrm{mg} / \mathrm{m}^{3}$ to $5 \mathrm{mg} / \mathrm{m}^{3}$ respirable dust (time weighted average for eight hours). Furthermore the British standard $\left(1 \mathrm{mg} / \mathrm{m}^{3}\right)$ is currently being reassessed. This controversy about which level of exposure to talc dust can be considered safe is mainly due to the lack of epidemiological studies in which the levels of exposure are measured with some precision. In acknowledgement of this fact, the French talc industry organised a systematic exposure assessment along with a respiratory survey of their staff, the results of which are presented here.

\section{Population and methods} STUDY DESIGN AND SUBJECTS

The study population consisted of all workers employed in the production and maintenance workshops of a talc producing factory situated in south west France between June 1989 and June 1990. During the annual medical check up, each subject was given a standardised respiratory health questionnaire combined with a questionnaire on smoking and occupational history. Furthermore each subject performed at least two valid spirometry tests under the supervision of the same technician who filled in the questionnaire. This technician had been trained according to the criteria of the American Thoracic Society for the spirometry and according to the recommendations of the European Coal and Steel Community (ECSC) for the questionnaire. For all subjects, a chest radiograph had been taken either at the date of their employment for the subjects who joined the company from 1982 onwards, or in 1987 for the subjects who joined the company before that date. In 1992, radiography was repeated for all subjects still employed at that date. Four subjects were excluded from the study population because of respiratory diseases unrelated to the exposure under study (two severe sequelae of tuberculosis treatment before hire, one sarcoidosis, and one farmer's lung) and four others did not participate in the study. Among the 166 remaining subjects, 139 had the second radiograph. Among the 27 subjects missing, 19 had retired in the meantime, the reason for leaving remained unknown for three subjects, three resigned, the other two were moved within the company. No attempt was made to follow up the retirees. Table 1 gives the general characteristics of the population. 
Table 1 General characteristics of the population

\begin{tabular}{|c|c|c|c|c|c|}
\hline & \multicolumn{2}{|c|}{ First study ( $n=166,8$ women) } & \multicolumn{3}{|c|}{ Second study ( $n=139,8$ women) } \\
\hline & $\begin{array}{l}\text { First } \\
\text { radiograph }\end{array}$ & Spirometry & $\begin{array}{l}\text { First } \\
\text { radiograph }\end{array}$ & Spirometry & $\begin{array}{l}\text { Second } \\
\text { radiograph }\end{array}$ \\
\hline $\begin{array}{l}\text { Age (SD) (y) } \\
\text { Duration of exposure (SD) } \\
\text { Smoking history: }\end{array}$ & $\begin{array}{l}36 \cdot 4(11 \cdot 8) \\
12 \cdot 0(11 \cdot 7)\end{array}$ & $\begin{array}{l}40 \cdot 2(10 \cdot 6) \\
15 \cdot 8(10 \cdot 2)\end{array}$ & $\begin{array}{c}34 \cdot 2(10 \cdot 2) \\
9 \cdot 6(9 \cdot 4)\end{array}$ & $\begin{array}{l}38 \cdot 2(9 \cdot 1) \\
13 \cdot 7(8 \cdot 0)\end{array}$ & $\begin{array}{l}40 \cdot 8(9 \cdot 1) \\
16 \cdot 2(8 \cdot 0)\end{array}$ \\
\hline $\begin{array}{l}\text { Non-smokers }(\mathrm{n}(\%)) \\
\text { Ex-smokers }(\mathrm{n}(\%)) \\
\text { Time since end of smoking (SD) (y) } \\
\text { Smokers (n (\%)) } \\
\text { Pack-years (SD) }\end{array}$ & $\begin{array}{l}59(36) \\
31(19) \\
10 \cdot 7(7 \cdot 0) \\
76(46) \\
13 \cdot 5(11 \cdot 3)\end{array}$ & $\begin{array}{l}58(35) \\
40(24) \\
11 \cdot 3(7 \cdot 8) \\
68(41) \\
18 \cdot 3(13 \cdot 1)\end{array}$ & $\begin{array}{l}46(33) \\
24(17) \\
9 \cdot 3(6 \cdot 4) \\
69(50) \\
12 \cdot 8(11 \cdot 0)\end{array}$ & $\begin{array}{l}45(32) \\
32(23) \\
10 \cdot 2(7 \cdot 3) \\
62(45) \\
17 \cdot 5(13 \cdot 1)\end{array}$ & $\begin{array}{l}44(32) \\
41(30) \\
10 \cdot 7(7 \cdot 5) \\
54(39) \\
18 \cdot 3(14 \cdot 3)\end{array}$ \\
\hline
\end{tabular}

\section{QUESTIONNAIRE AND SPIROMETRY}

The respiratory questionnaire was based on the ECSC questionnaire. The questionnaire considered past and present chronic bronchitis, cough, wheeze, and dyspnoea. Chronic bronchitis was defined as cough and phlegm for at least three months each year for not less than two successive years. The term chronic cough or phlegm was used to define those subjects whose cough or phlegm did or did not fulfil the criteria for chronic bronchitis. Dyspnoea on exertion was considered to be present when the subjects complained of breathlessness while walking up a slight hill. Non-smokers were defined as subjects who had never regularly smoked one or more cigarettes a day or had smoked one or more cigarettes for less than one year. Current smokers were subjects who reported regular smoking of one or more cigarettes a day for at least one year. Ex-smokers were subjects who reported smoking one or more cigarettes a day regularly in the past but who had stopped smoking at least one year before the study. Pack-years were computed at the date of the examination and between the two radiographs to assess the quantitative impact of smoking.

The occupational history consisted of a list of jobs with dates covering the whole of the subjects' working life. The jobs preceding employment in the factory were classified into five categories: agricultural, exposed to mineral dust (mines), exposed to other dust, building industry, no known exposure. For each period of work in the talc industry, the detailed job title and the workplace were recorded.

The spirometry was performed with a vitalograph that had been checked at the laboratory of the Institute of Occupational Health (Toulouse) at the start of the study. During the study it was calibrated every three months with a calibrated 31 syringe. Forced vital capacity (FVC), forced expiratory volume in one second $\left(\mathrm{FEV}_{1}\right)$ and maximal mid-expiratory flow (MMEF) were measured manually on the curve produced by the vitalograph. The quality and repeatability of the measures were assessed visually by one of us (MR) according to professional judgement independently from any exposure information and before any analysis. When they were considered insufficient, the data were excluded from the data base. The measurements were expressed as standardised residuals (observed- predicted/residual SD) - that is, in numbers of residual SDs (RSDs) with the predicted values and the RSD from the European Respiratory Society after the recommendations of Quanjer et al. ${ }^{1}$ For men, RSD $=0.611$ for FVC and 0.51 1/s for FEV 1 .

\section{CHEST RADIOGRAPHS}

The chest radiographs (full sized chest radiograph) were interpreted in two separate trials: (a) in 1991, the chest radiographs taken in 1987 for all subjects hired before 1982 and still at work in 1987; (b) in 1992, the radiographs taken in 1992 for all subjects of the study population and the films taken at the time of employment for all subjects hired after 1982 (not in the first trial).

In both trials, the radiographs were interpreted by the same three independent medical readers-trained with the 1980 International Labour Office (ILO) classification of pneumoconioses ${ }^{2}$-reading several thousand films a year, blind to occupational, personal, and medical characteristics of the subjects. Films were allocated to the readers in the same random order. The readers' classifications were recorded by a clerical assistant on a recording sheet and then computerised. To increase the consistency of interpretation, the three readers interpreted a sample of films by consensus before the main and independent reading. These films have been included as "trigger films" as described by Trethowan et al. ${ }^{3}$ Also, as an exercise, a sample of films read in the first trial were reinterpreted in the second trial. Variability between and within readers was measured (not covered here).

A median reading was determined for each variable (film quality, profusion, and shape and size of small opacities, categories of large opacities, any pleural change, and any additional symbol).

\section{INDUSTRIAL PROCESS}

The crude talc is extracted in a nearby open cast pit from which it is transported directly to the factory through an overhead cable. The extracted ore consists of a mixture of talc $\left(\mathrm{Mg}_{9} \mathrm{Si}_{4} \mathrm{O}_{10}(\mathrm{OH})_{2}\right)$, chlorite $\left((\mathrm{Mg}, \mathrm{Fe})_{5} \mathrm{Al}\right.$ $\left.\left[\mathrm{AlSi}_{4} \mathrm{O}_{10}\right][\mathrm{OH}]_{8}\right)$, some dolomite (<3\%), sometimes quartz $(<3 \%)$, and traces of calcite, apatite, pyrite, and mica. Amphiboles have never been detected according to the CTFA J4-1 method. ${ }^{4}$

The talc ore is sorted immediately after being extracted into different grades of talc. 
Figure 1 An example of exposure assessment. At the date of spirometry, the estimated cumulative exposure is $(85-74) \times 30$ $+(87-85) \times 15+(90-87)$ $\times 0.5=301.5 \mathrm{y} \mathrm{mg} / \mathrm{m}^{3}$.

A Two workplaces

General cleaning

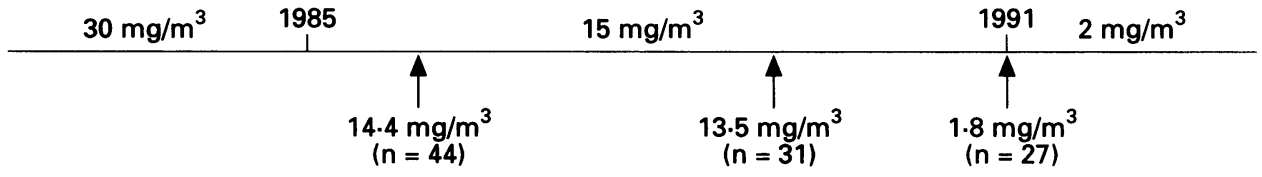

Handling railway wagons

$0.5 \mathrm{mg} / \mathrm{m}^{3}$

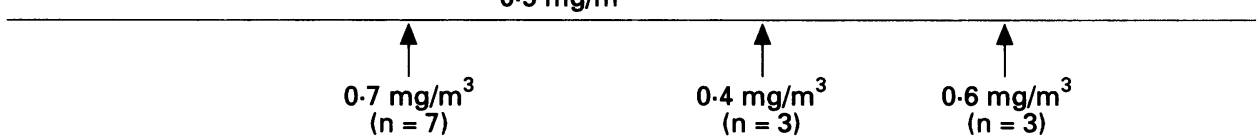

B An individual job history

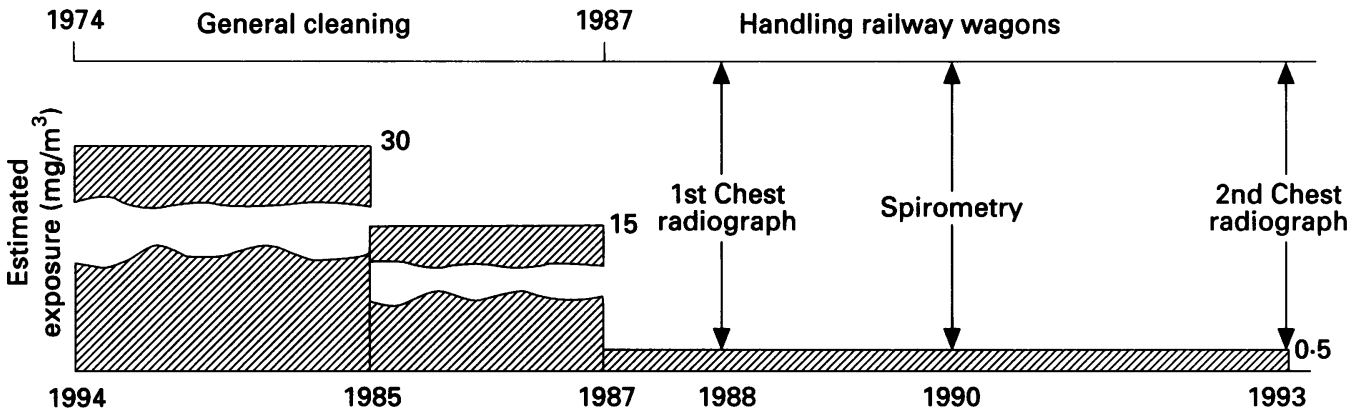

The first step of the process consists in drying the ore in ovens between 90 and $110^{\circ} \mathrm{C}$ depending on the moisture level. The dry ore is then ground finely (median diameter from $10 \mu \mathrm{m}$ to $1 \mu \mathrm{m}$ ) according to the quality required; finally it is packaged either by bagging or by loading the trucks and railway wagons directly in bulk.

EXPOSURE ASSESSMENT

In 1986, 1989, and 1991 systematic exposure measurements were taken for every workplace and job in the production and maintenance areas with the CIP10 personal dust sampler ${ }^{5}$ worn by the worker for at least a half shift (four hours). In each measurement campaign, at least two shifts were thus characterised for every worker in the production and maintenance workshops, in 1986 the clerical workers were also included. The dust sampler measures the gravimetric dust concentration collected at a flow rate of $10 \mathrm{l} /$ minute. The head of the sampler acts as a particle selector that enables the respirable (alveolar) dust fraction to be determined. The particles are collected in a rotating cup filled with polyurethane foam. The variation of the cup's mass (difference of weight before and after sampling) gives the total amount of alveolar dust collected. As the weight of the polyurethane and the plastic cup are sensitive to air humidity, three reference cups were used that were weighted simultaneously with the cups used for sampling. The mass difference was corrected by subtracting the mean difference of the reference cups.

The second stage consisted of drawing up a list of all the combinations of job titles and workplaces with start and stop dates. A qualitative analysis of this list led to the definition of 52 exposure groups after checking back for imprecise or incoherent data.

For each of these groups that still existed in 1986, we analysed the corresponding exposure measurements both globally and year by year to detect possible trends. Each series of measurements was described by its arithmetic mean, its geometric mean and $S D$, and the estimate of the mean assuming a log normal distribution. ${ }^{6}$ Every data set in which the geometric SD (GSD) exceeded three, or in which the arithmetic mean was very different from the estimated mean, was checked for possible outliers that were compared with the original records. These were only suppressed if independent evidence was found for their invalidity.

Furthermore a historical description was available for every workplace, which indicated the technological changes, the aspiration devices, and qualitative levels of dust. These were obtained by interview of the long term employees of the factory who compared the past exposures with the present measured conditions. Furthermore, some area dust sampling measurements (from different devices) existed since 1954. These different methods of collecting information resulted in imprecise estimates of past exposures.

From a combination of these methods, up to three levels of exposure by calendar period were attributed to every exposure group. Cumulative exposure indices for each subject were computed at the dates of the spirometry 


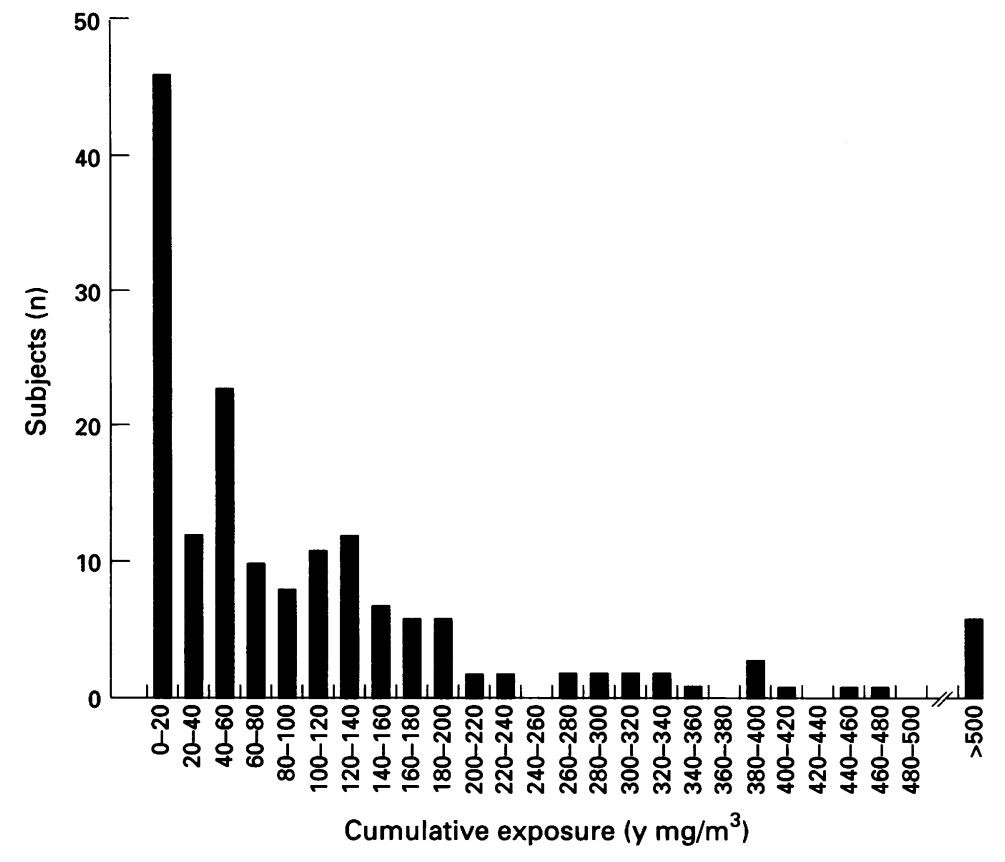

Figure 2 Range of cumulative exposures

and radiographs as well as between spirometry tests and between radiographs by multiplying the concentrations extracted from the preceding job exposure matrix by the corresponding number of years. Figure 1 gives an example of this procedure. Exposure groups were defined for each index with cut off points of 20,50 , and $150 \mathrm{y} \mathrm{mg} / \mathrm{m}^{3}$ for the total exposure and cut off points of 4,9 , and $15 \mathrm{mg} / \mathrm{m}^{3}$ for the longitudinal study. The cut off points were chosen to give rough quartiles of the population.

STATISTICAL METHODS

An initial analysis consisted of the questionnaire, spirometry, and radiograph. The prevalence of symptoms or small opacities was analysed in a multiple logistic regression that included potentially confounding variables (age, smoking categories, pack-years) and coded cumulative exposure.

The analysis of the lung function data used a multiple linear regression model of the standardised residuals. The model did not include age and height as they were accounted for in the standardisation, but did include smoking variables and the individual cumulative exposure. The flow variables $\mathrm{FEV}_{1}, \mathrm{MMEF}$, and $\mathrm{FEV}_{1} / \mathrm{FVC}$ were adjusted quantitatively for smoking by fitting the number of pack-years and time since the end of smoking, as it is known that smoking is mostly related to an obstructive syndrome. On the other hand, as the FVC is, among healthy subjects, relatively unaffected by smoking, its analysis included solely the qualitative smoking categories.

The evolution of the radiographs was described in four categories. A first group consisted of the subjects without any opacity compatible with a diagnosis of pneumoconiosis (profusion higher than $0 / 1$ ) at both study dates, a second group of subjects in which this reading had been coded the first time and not coded the second time, in the third group pneumoconiosis appeared between the two radiographs, in the fourth it was present on both occasions.

A logistic regression was used to see if the appearance of the opacity (group 3) was related to the cumulative exposure and cumulative smoking between the study dates.

The description and analysis of data was performed with SAS $^{7}$ and EGRET ${ }^{8}$ software.

\section{Results}

EXPOSURE ASSESSMENT

A total of 1440 personal samples was taken between 1986 and 1991. Thus among 52 exposure groups, 49 could be characterised by actual individual measurements. The measured mean exposure ranged from $0.5 \mathrm{mg} / \mathrm{m}^{3}$ for secretaries, managerial staff, and outdoor workers who handle the railway wagons to 15 for the cleaning staff until 1991. Nowadays only one exposure group of maintenance workers that consists of four subjects is estimated to have a mean exposure of above $5 \mathrm{mg} / \mathrm{m}^{3}$ although the probability of exceeding this level remains above $10 \%$ for most maintenance and for some production exposure groups. This is explained by the high variability of the exposure measurements among maintenance workers intrinsic to these occupations: eight out of 10 exposure groups in the maintenance workshop had measurements with GSDs $>3$. The measurements were found to be more homogenous within the production exposure groups. When the $\log$ concentrations were analysed in an analysis of variance, the grouping was found to be very informative especially in the first measurement campaign. The ratio of between group variance and within group variance (the $F$ statistic) decreased from 10.2 in 1986 to 2.3 in 1991 in the production area and from 24.9 to 4.9 among the maintenance groups. This reflects the efforts to reduce the dust levels both by the introduction of centralised aspiration devices and by the introduction of new work procedures. These efforts have resulted in lower and more homogenous working conditions across the factory. On the other hand this variance ratio has not been found to be significant when examining the variability between workers within exposure groups. After assigning a fixed level to each subject based on the group measurements as discussed, the present geometric mean exposure of the population is 1.87 (GSD 2.5$) \mathrm{mg} / \mathrm{m}^{3}$.

In the past, mean exposures up to 60 $\mathrm{mg} / \mathrm{m}^{3}$ were estimated especially in the job of storing jute talc bags in wagons. Among still existing workplaces, the highest past exposures were estimated for the cleaning staff before $1985\left(30 \mathrm{mg} / \mathrm{m}^{3}\right)$ and for a sacking workplace before 1975 and for a workplace at the dryer before 1975 (both $20 \mathrm{mg} / \mathrm{m}^{3}$ ). These very different exposures led to a large spread in cumulative exposures (fig 2 ).

RESPIRATORY SYMPTOMS AND LUNG FUNCTION Analysis by symptom (table 2) showed an increased prevalence of chronic bronchitis 
Table 2 Prevalence of symptoms and standardised functional variables (men only) according to cumulative exposure

\begin{tabular}{|c|c|c|c|c|c|c|}
\hline & $\begin{array}{l}<20 \\
\left(y m g / m^{3}\right) \\
n=46\end{array}$ & $\begin{array}{l}20-50 \\
\left(y \mathrm{mg} / \mathrm{m}^{3}\right) \\
n=25\end{array}$ & $\begin{array}{l}50-150 \\
\left(y \mathrm{mg} / \mathrm{m}^{3}\right) \\
n=54\end{array}$ & $\begin{array}{l}>150 \\
\left(y \mathrm{mg} / \mathrm{m}^{3}\right) \\
n=41\end{array}$ & $\begin{array}{l}\text { Slopel } \\
100 y \mathrm{mg} / \mathrm{m}^{3} \\
\text { (SEM) }\end{array}$ & Pvalue \\
\hline $\begin{array}{l}\text { Symptoms (n (\%)) } \\
\text { Chronic bronchitis } \\
\text { Chronic cough or phlegm } \\
\text { Dyspnoea } \\
\text { Wheeze }\end{array}$ & $\begin{array}{l}0(0) \\
4(8 \cdot 7) \\
2(4 \cdot 4) \\
2(4 \cdot 4)\end{array}$ & $\begin{array}{l}1(4) \\
5(20) \\
2(8) \\
1(4)\end{array}$ & $\begin{array}{l}7(13) \\
14(35 \cdot 7) \\
9(17) \\
2(3 \cdot 7)\end{array}$ & $\begin{array}{l}1(2) \\
6(14 \cdot 6) \\
6(14 \cdot 6) \\
0(0)\end{array}$ & & $\begin{array}{l}0.22^{\star} \\
0.43 \dagger \\
0.039 \ddagger \\
>0.5^{\star}\end{array}$ \\
\hline $\begin{array}{l}\text { Valid spirometries } \\
\text { Functional variables (mean (SD)): }\end{array}$ & 36 & 20 & 44 & 36 & & \\
\hline $\begin{array}{l}\text { FVC } \\
\text { FEV }_{1} \\
\text { FEV }_{1} / \text { FVC } \\
\text { MMEF }\end{array}$ & $\begin{array}{l}1.33(1.28) \\
1.22(1.21) \\
0.25(0.70) \\
0.66(1.58)\end{array}$ & $\begin{array}{l}0.82(1.04) \\
0.77(1.22) \\
0.27(0.79) \\
0.36(1.41)\end{array}$ & $\begin{array}{r}1.10(1.07) \\
0.74(1.17) \\
-0.04(0.80) \\
-0.19(1.15)\end{array}$ & $\begin{array}{r}0.65(1.03) \\
0.50(1.06) \\
0.24(0.75) \\
-0.06(1.12)\end{array}$ & $\begin{array}{l}-0.24(0.10) \Phi \\
-0.26(0.11) \\
-0.06(0.07) \\
-0.26(0.12)\end{array}$ & $\begin{array}{l}0.015 \\
0.014 \\
0.40 \\
0.032\end{array}$ \\
\hline
\end{tabular}

* Test for trend in a logistic regression; ttest for trend in a logistic regression after adjustment for smoking and pack-years; ftest for trend in a logistic regression afte adjustment for age and smoking; fin a linear regression model including smoking; fin a linear regression model including pack-years and time since the end of smoking.

Table 3 Radiological opacities (ILO) at the first radiograph according to cumulative exposure at this date and to previous exposure to mineral dust

\begin{tabular}{|c|c|c|c|c|c|c|c|}
\hline \multirow[b]{2}{*}{ ILO code } & \multicolumn{5}{|c|}{ Talc exposure in y $\mathrm{mg} / \mathrm{m}^{3}$} & \multicolumn{2}{|c|}{$\begin{array}{l}\text { Former exposure } \\
\text { to mineral dust }\end{array}$} \\
\hline & Non-exposed ${ }^{*}$ & $<20$ & $20-50$ & $50-150$ & $>150+$ & No & Yes \\
\hline $0 / 0$ & 43 & 9 & 6 & 17 & 12 & 85 & 2 \\
\hline $0 / 1$ & 12 & 6 & 10 & 21 & 10 & 51 & 8 \\
\hline $1 / 0$ & 0 & 1 & 0 & 1 & 7 & 8 & 1 \\
\hline $1 / 1$ & 0 & 0 & 0 & 4 & 6 & 9 & 1 \\
\hline $1 / 2$ & 0 & 0 & 0 & 0 & 1 & 1 & 0 \\
\hline
\end{tabular}

^Radiograph taken when hired.

and cough or phlegm in the cumulative exposure category from 50 to $150 \mathrm{y} \mathrm{mg} / \mathrm{m}^{3}$, this was not confirmed in the highest exposure group. When this symptom (which includes chronic bronchitis) was analysed in a multiple logistic regression that included smoking category (non-smoker, ex-smoker, and current smoker) and pack-years, the trend was far from significant. This was not the case for dyspnoea where the increasing trend found was confirmed by the logistic regression model that included age and smoking category.

Only 138 spirometry tests $(83.6 \%)$ were considered to be of sufficient quality to be included in the statistical analysis.

A significant downward trend was found for the standardised FVC in a linear regression model that included (or excluded) the smoking categories. A similar trend was found both for $\mathrm{FEV}_{1}$ and MMEF after adjustment for smoking categories, pack-years, and time since the end of smoking for ex-smokers. This was not confirmed for the $\mathrm{FEV}_{1} / \mathrm{FVC}$ ratio, which decreased only slightly with increasing exposure.

Table 4 Logistic model for radiological opacities (ILO) at the first radiograph

\begin{tabular}{|c|c|c|c|c|}
\hline & \multicolumn{2}{|c|}{ Any opacity including $0 / 1$} & \multicolumn{2}{|c|}{ Any opacity excluding $0 / 1$} \\
\hline & Coefficient & $O R(95 \% C I)$ & Coefficient & OR $(95 \% C I)$ \\
\hline $\begin{array}{l}\text { Intercept } \\
\text { Smoking: }\end{array}$ & $-2 \cdot 71$ & - & $-8 \cdot 80$ & - \\
\hline Non-smoker & 0 & 1 & 0 & 1 \\
\hline $\begin{array}{l}\text { Ex-smoker } \\
\text { Smoker }\end{array}$ & $\begin{array}{l}0.44 \\
0.31\end{array}$ & $\begin{array}{l}1.56(0.58-4 \cdot 17) \\
1.37(0.63-2.97)\end{array}$ & $\begin{array}{l}-0.20 \\
-0.82\end{array}$ & $\begin{array}{l}0.82(0.20-3.27) \\
0.44(0.12-1.69)\end{array}$ \\
\hline Age (y) & 0.040 & $1.041(0.996-1.088)$ & 0.093 & $1.098(1.02-1 \cdot 18)$ \\
\hline $\begin{array}{l}\text { Former exposure to } \\
\text { mineral dust } \\
\text { Coded cumulative }\end{array}$ & $1 \cdot 86$ & $6 \cdot 40(1 \cdot 23-33 \cdot 3)$ & -0.30 & $0 \cdot 74(0 \cdot 10-5 \cdot 51)$ \\
\hline exposure to talc & $0 \cdot 33$ & $1.39(1.06-1.84)$ & 0.97 & $2 \cdot 65(1.25-5 \cdot 64)$ \\
\hline
\end{tabular}

\section{RADIOLOGICAL FINDINGS}

Four pleural abnormalities were coded by at least two readers, including one chest wall pleural thickening and three pleural thickenings in the interlobar fissures (pi). One was found on a radiograph taken when the subject was hired, the three others had cumulative exposures estimated at 95, 160, and 240 $\mathrm{y} \mathrm{mg} / \mathrm{m}^{3}$. Only the first had a second radiograph, and no pleural abnormality was found on this second radiograph.

All observed opacities were coded between $0 / 1$ and $1 / 2$ according to the ILO classification for pneumoconiosis. The dominant shapes of the opacities were mostly irregular ( $8.9 \%$ only were coded $p$ or $q)$ and no opacity was coded larger than $3 \mathrm{~mm}$ (the only codes used were $p, q$ and $s, t)$. Tables 3 and 4 give the opacities in terms of cumulative exposure to dust and former exposure to mineral dust. Both were found to be significantly related to the prevalence of opacities in a multiple logistic model although the effect of smoking was less obvious.

The prevalence of small opacities was higher in the second radiograph (tables 5 and 6) than in the first radiograph with 11 new opacities compatible with a diagnosis of pneumoconiosis ( $1 / 0$ and above) $v$ two images that were not recognised as such in the second radiological image. In the second series of radiographs all images were coded $s$ or $t$ including the 11 new opacities. There was no evidence that this was attributable to cumulative exposure to dust as the highest mean exposures were seen in the groups without opacities with higher profusion than $1 / 0$ in the second radiograph. In the logistic analysis of any increase in profusion, the effect of the cumulative exposure groups was significantly 
Table 5 Longitudinal study: radiological findings: cross tabulations of the two coded profusions

\begin{tabular}{lrrll}
\hline & \multicolumn{5}{l}{ Second radiograph } \\
\cline { 2 - 5 } First radiograph & $0 / 0$ & $0 / 1$ & $1 / 0$ & $1 / 1$ \\
\hline $0 / 0$ & 53 & 22 & 2 & 0 \\
$0 / 1$ & 18 & 26 & 7 & 2 \\
$1 / 0$ & 1 & 1 & 2 & 0 \\
$1 / 1$ & 0 & 0 & 3 & 1 \\
$1 / 2$ & 0 & 0 & 1 & 0 \\
\hline
\end{tabular}

negative. In contrast with this, smoking was positively and significantly related to this increase: 10 out of 11 pneumoconiosis-like new images were from smokers. Among the three subjects who resigned, one had a 1/0 image and the mean FVC was somewhat lower than the remaining population $(0.074$ SD) although non-significant.

\section{Discussion}

Several old epidemiological studies have suggested that exposure to talc can lead both to a pneumoconiosis and to chronic respiratory impairment. $^{9-17}$ This impairment was usually considered to be of the restrictive type although Fine et al also described an obstructive syndrome among smokers. ${ }^{18}$ Yet only two studies ${ }^{18-20}$ had quantitative estimates of the exposure to respirable dust, which are prerequisites to any threshold limit value (TLV) proposal. We shall thus focus the discussion on the comparison with the findings of those studies and the earlier studies carried out in this factory. ${ }^{21} 22$

A main strength of the present study is the good quantitative knowledge of the exposure, which relies on a systematic and repeated exposure assessment through personal samplers worn over full shifts and the precise coding of the work histories. This enabled us to determine homogenous exposure groups although homogeneity as measured by the GSD is less certain among maintenance workers whose different tasks lead to intrinsically different exposures. The quantitative exposure estimates as used in the longitudinal study should therefore be accurate. The estimation of past exposures is less precise given that they are not based on actual personal measurements. Some area sampling data do exist since $1954^{22}$; thus at least the order of magnitude of the estimation should be correct and the differences between exposure groups, as measured in 1986, are so great that even if some errors in the estimates of exposures have occurred, their impact should be minor. This is further validated by the fact that the prevalence of small opacities is strongly correlated with exposure groups. It is highly unlikely that the exposure-response effects found could be due to change in the chemical composition of the crude talc as it always came from the same deposit nearby and its transformation does not alter its composition. Neither is it plausible that exposure through ingestion may have been very different in the past from the present.

The exposures of the Vermont millers and miners as reported by Boundy et al ${ }^{19}$ were very different from the present study. Not only were the estimated exposures much lower than in our study but the GSD never exceeded 2.4 despite the fact that all workplaces were pooled, which seems to indicate an overall homogeneity of exposures within the three mills, which was not found here.

A possible weakness of our study is the less than optimal quality of the spirometric tests that led to the exclusion of 30 subjects in this analysis. The excluded tests could possibly come from subjects with respiratory diseases. This is to some extent confirmed in the analysis of the functional variables of the subjects excluded, but it does not seem legitimate to reincorporate subjects who have been excluded because of their lack of repeatability in the quality control before analysis.

A usual weakness of cross sectional studies - that is, self selection on a health basis, is unlikely here. The talc factory is situated in an isolated valley near the deposit and virtually no other industry, except for some aluminium foundries in which the working conditions were more severe, existed near the study site. We do not think that the absence of an effect of the cumulative exposure on chronic bronchitis is attributable to this phenomenon. The two subjects excluded with known respiratory diseases unrelated to the exposure both had a $0 / 1$ opacity and cumulative exposures of 66 and $268 \mathrm{y} \mathrm{mg} / \mathrm{m}^{3}$. Whereas it is not clear whether their opacity is due to their illness or their exposure, a conservative approach leaves them out.

The results of the lung function tests suggest the hypothesis that high exposure to talc induces a restrictive syndrome rather than an obstructive one. The effect of obstruction should reduce the $\mathrm{FEV}_{1} / \mathrm{FVC}$ ratio whereas a restrictive syndrome could arguably reduce $\mathrm{FEV}_{1}$ through the simple effect of reduced volumes but it would not alter the $\mathrm{FEV}_{1} / \mathrm{FVC}$

Table 6 Longitudinal study: smoking and exposure characteristics by evolution of the profusion

\begin{tabular}{|c|c|c|c|c|}
\hline & $\begin{array}{l}0 / 0,0 / 1 \\
n=119\end{array}$ & $\begin{array}{l}1 / 0,1 / 1 \\
\rightarrow 0 / 0,0 / 1 \\
n=2\end{array}$ & $\begin{array}{l}0 / 0,0 / 1 \\
\vec{n}=1 / 0,1 / 1 \\
n=11\end{array}$ & $\begin{array}{l}1 / 0,1 / 1,1 / 2 \\
n=7\end{array}$ \\
\hline $\begin{array}{l}\text { Age at second radiograph } \\
\text { Smokers } n(\%) \\
\text { Cumulative pack-years between radiographs } \\
\text { Cumulative pack-years at second radiograph } \\
\text { Cumulative exposure between }\end{array}$ & $\begin{array}{l}40 \cdot 6(8 \cdot 9) \\
55(46 \%) \\
2 \cdot 5(4 \cdot 1) \\
11 \cdot 2(13 \cdot 8) \\
23 \cdot 7(31 \cdot 4)\end{array}$ & $\begin{array}{l}45 \cdot 4(7 \cdot 0) \\
-\quad \\
-\quad 8 \cdot 4(8 \cdot 5)\end{array}$ & $\begin{array}{l}43 \cdot 4(9 \cdot 4) \\
10(91 \%) \\
3 \cdot 3(1 \cdot 6) \\
17 \cdot 3(9 \cdot 8) \\
12 \cdot 1(8 \cdot 3)\end{array}$ & $\begin{array}{l}51 \cdot 7(6 \cdot 8) \\
7(43 \%) \\
2 \cdot 3(3 \cdot 7) \\
24 \cdot 7(17 \cdot 7) \\
15 \cdot 8(16 \cdot 1)\end{array}$ \\
\hline $\begin{array}{l}\text { Mean concentration of exposure between } \\
\text { radiographs }\left(\mathrm{mg} / \mathrm{m}^{3}\right)\end{array}$ & $3 \cdot 5(3 \cdot 8)$ & $1.5(1 \cdot 3)$ & $2 \cdot 3(1 \cdot 5)$ & $3 \cdot 3(3 \cdot 4)$ \\
\hline Cumulative exposure at second radiograph & $92 \cdot 0(110 \cdot 6)$ & $102 \cdot 0(118 \cdot 7)$ & $72 \cdot 1(45 \cdot 2)$ & $255 \cdot 7(205 \cdot 7)$ \\
\hline
\end{tabular}


ratio as is the case here. The spirometric findings are unlikely to be confounded by smoking as the slope with cumulative exposure is nearly identical in all three smoking categories. The fact that the prevalence of dyspnoea is greater in the high exposure groups, even after adjustment for age, does not throw any further light on the discussion so far. Yet the absence of any increased prevalence of chronic bronchitis with high exposures indirectly supports our interpretation of the spirometric findings. On the other hand, contrary to the findings of Fine $e t a l,{ }^{18}$ the prevalence of wheeze is low in our population and no relation exists with the exposure groups. Only four subjects $(2 \cdot 5 \%)$ reported dyspnoea while walking at their own pace on level ground (grade 3), moreover this feature is much reduced when individual exposure estimates were used. Despite the basically similar conclusion, some differences exist between our study and studies by Fine $e t a l^{18}$ and Wegman et al. ${ }^{20}$ Wegman et al found that ratios of observed divided by predicted values were generally lower than one despite lower dust levels, although this could be attributed to differences in the reference equations. Fine et al reported a higher prevalence of respiratory symptoms but the number of smokers in their population of workers exposed to talc was higher and the assumption that exposure was restricted to talc and had been constant historically seems questionable in a study of rubber workers. ${ }^{18}$

The earlier studies of the present population by Leophonte et al are consistent with our study although the reported lung function measurements are lower in the 1980 study. ${ }^{21} 22$ This can to a certain extent be explained by the choice of reference equations; the ECSC reference values ${ }^{23}$ used by Leophonte et $a l^{21}$ are higher than the more recent ones proposed by Quanjer et al, ${ }^{1}$ as has been noted by Préfaut and Peslin. ${ }^{24}$ The cross sectional analysis of the initial radiological data confirms that high exposure leads to small opacities. They cannot be attributed to silica contamination as the characteristic regular opacities were few and disappeared altogether in the second series of radiographs. There was complete agreement about this between readers. The overall agreement of size and shape between readers was good with $\kappa$ varying from 0.33 to 0.44 . A surprising finding was that smoking did not seem to be a determinant in the prevalence of opacities possibly because the exposure pattern distorted this established relation; a slight and non-significant interaction was nevertheless found between smoking and cumulative exposure in the logistic regression of the prevalence of opacities. In the present population no high profusions (ILO codes $2 / 1$ and above) were found, contrary to the previous study by Leophonte and Didier. ${ }^{22}$ Among subjects with an image consistent with a diagnosis of pneumoconiosis (ILO code $1 / 0$ and above), all except one had been exposed to at least $5 \mathrm{mg} / \mathrm{m}^{3}$; the $1 / 0$ code for this last subject was not confirmed in the second radiograph. The prevalence of irregular opacities in our study is comparable with the findings of Wegman et $a^{20}$ although they found the number of regular opacities to be much higher. The longitudinal results are somewhat at odds with the previous findings as 11 new images consistent with a diagnosis of pneumoconiosis appeared, all of which were in subjects with a relatively low exposure, but nearly all of whom were smokers. This, and the fact that some large studies (Graham et al, ${ }^{25}$ Castellan et $a l^{26}$ ) showed very low prevalences of small opacities among blue collar workers with no or low exposure, suggests a possible synergy of smoking and exposure to talc dust at present levels, but it is possible that the results would have been different had retirees been followed up. This incidence is not attributable to changes in reading levels as among $470 / 1$ images, nine were coded $0 / 0$, three $1 / 0$ and one $1 / 1$ at the second reading. Among $171 / 0$ or $1 / 1$ images, 13 stayed in this category and four were coded $0 / 1$. Thus reading levels were stable with a slight tendency for less severe codes in the second reading. On the other hand a review by Dick et al states that "scanty irregular opacities are not uncommonly observed, they are found in association with cigarette smoking and dust exposure but the type of dust seems to be of little moment" ${ }^{27}$

We thank the referees for helpful comments and Dr Bohadana for his help in the interpretation of the respiratory data.

1 Quanjer PH, Tammeling GJ, Cotes JE, Pedersen OF Peslin $R$, Yernault JC J, Cotes Peslin R, Yernault JC. Lung volumes
ventilatory flows. Eur Respir $\mathcal{f} 1993 ; 6: 5-40$.

2 International Labour Organisation. International classifica tion of radiographs of pneumoconioses. Geneva: International Labour Office, Occupational Safety and Health, 1980. Series No 22 rev)

3 Trethowan WN, Burge PS, Harrington JM, Calvert I, Rossiter CE. A study of the respiratory health of employees in seven European ceramic fibre manufacturing plants. Final report to the European Ceramic Fibre Industries Association. University of Birmingham: Institute of Occupational Health, 1989.

4 Ferret J, Moreau P. Mineralogy of talc deposits. In: Bignon J, ed. Health related effects of phyllosilicates. Berlin Bignon J, ed. Health related effects of phyllosilicates. Berlin: G21).

5 Courbon P, Wrobel R, Fabries JF. A new individual respirable dust sampler: the CIP 10. Ann Occup Hyg 1988;32:129-43.

6 Waters MA, Selvin S, Rappaport SM. A measure of goodness-of-fit for the lognormal model applied to occupational exposures. Am Ind Hyg Assoc f 1991;52:493-502.

7 SAS Institute. SAS/STAT users guide, version 6. Cary, NC SAS Institute, 1989.

8 EGRET Software Program, version 0.26.6. Seattle: Statistics and Epidemiology Research Corporation, 1990.

9 Dreessen WC, Dalla Valle JM. The effects of exposure to dust in two Georgia talc mills and mines. Public Health Rep 1935;50:131-43.

10 Hogue WL, Mallette FS. A study of workers exposed to talc and other dusting compounds in the rubber industalc and other dusting compounds in the
try. $\mathcal{F}$ Ind Hyg Toxicol 1949;31:359-64.

11 Mann B, Deasy JB. Talc pneumoconiosis in the textile industry, $B M F$ 1954;ii: 1460-1.

12 Kipling MD, Bech AO. Talc pneumoconiosis. Transactions of the Association of Industrial Medical Officers 1960 10:85-93.

13 Kleinfeld M, Messite J, Shapiro J, Kooyman O, Swencick R. Lung function in talc workers. Arch Environ Health 1964;9:559-66.

14 Kleinfeld M, Messite J, Kooyman O, Shapiro J Pulmonary ventilatory function in talcosis of lung. Dis Chest 1964;46:592-8.

15 Kleinfeld M, Messite J, Shapiro J, Swencicki R. Effects of talc dust inhalation on lung function. Arch Environ Health 1965;10:431-7.

16 Miller A, Teirstein AS, Bader ME, Bader RA, Selikoff IJ Talc pneumoconiosis. Am F Med 1971;50:395-402.

17 Kleinfeld M, Messite J, Langer AM. A study of workers exposed to asbestiform minerals in commercial talc manufacture. Environ Res 1973;6:132-43.

18 Fine LJ, Peters JM, Burgess WA, Diberadinis LJ. Studies of respiratory morbidity in rubber workers. Arch Environ Health 1976;31:195-200. 
19 Boundy MG, Gold K, Martin KP, Burgess WA, Dement JM. Occupational exposures to non-asbestiform talc in Vermont. Dusts and disease. In: Lemen R, Dement JM, eds. Proceedings of the conference on occupational exposures eds. Proceedings of the conference on occupational exposures to fibrous and particulate dust and their extension in

20 Wegman DH, Peters JM, Boundy MG, Smith TJ. Evaluation of respiratory effects in miners and millers exposed to talc free of asbestos and silica. $\mathrm{Br} \mathcal{F}$ Ind $\mathrm{Med}$ 1982;39:233-8.

21 Leophonte P, Fernet P, Pincemin J, Mousset J, Rellier R, Delaude A. La pathologie respiratoire chronique des travailleurs du talc. Revue Française des Maladies Respiratoires 1980;8:43-5.

22 Leophonte P, Didier A. French talc pneumoconiosis. In: Bignon J, ed. Health related effects of phyllosilicates. Berlin: Springer-Verlag, 1990:203-9. (NATO ASI series, vol G21).
23 Cara M, Hentz P. Aide-mémoire of spirographic practice for examining ventilatory function. 2nd ed. Luxembourg: Commission of the European Communities, 1971 . Commission of the European Communities,
(Industrial Health and Medicine, Series No 11.)

24 Préfaut C, Peslin R. L'exploration du souffle ou mesure des volumes pulmonaires et des débits bronchiques. Rev Mal Resp 1986;3:323-32.

25 Graham WGB, Ashikaga T, Hemenway D, Weaver S, O'Grady RV. Radiographic abnormalities in Vermont granite workers exposed to low levels of granite dust. Chest 1991;100:1507-14.

26 Castellan RM, Sanderson WT, Petersen MR. Prevalence of radiographic appearance of pneumoconiosis in an unexposed blue collar population. Am Rev Respir Dis 1985;131:684-6.

27 Dick JA, Morgan WKC, Muir DFC, Reger RB, Sargent $\mathrm{N}$. The significance of irregular opacities on the chest roentgenogram. Chest 1992;60:102-251.

\section{Rejected manuscripts}

From February 1994, authors whose submitted articles are rejected will be advised of the decision and one copy of the article, together with any reviewers' comments, will be returned to them. The fournal will destroy remaining copies of the article but correspondence and reviewers' comments will be kept. 